\title{
Ge/Si структуры с упорядоченными квантовыми точками, встроенными в микрорезонаторы
}

\author{
Ж.В. Смагина ${ }^{1)}$, В.А. Зиновьев ${ }^{1)}$, В.А. Армбристер ${ }^{1)}$, Е.Е. Родякина ${ }^{1,2)}$, Б.И. Фомин ${ }^{1)}$, \\ М.В. Степихова ${ }^{3)}$, А.Н. Яблонский ${ }^{3)}$, А.В. Новиков ${ }^{3)}$, А.В. Двуреченский ${ }^{1,2)}$ \\ ${ }^{1}$ Институт физики полупроводников им. Ржанова СО РАН, Новосибирск, пр. Ак. Лаврентьева, 13 \\ ${ }^{2}$ Новосибирский государственный университет, Новосибирск, ул. Пирогова, 2 \\ ${ }^{3}$ Институт физики микроструктур РАН, Нижегородская обл., д. Афонино, Кстовский район, ул. \\ Академическая, д. 7 \\ тел:+7 (383) 333-2519, факс:+7 (383) 333-2466, эл.nочта: smagina@isp.nsc.ru
}

DOI 10.34077/RCSP2019-74

В настоящее время полупроводниковые источники излучения, в том числе лазеры, создаются на основе прямозонных материалов. Однако существует целый класс задач, для решения которых необходимо реализовать источники излучения на основе непрямозонных полупроводников. Гетероструктуры $\mathrm{Ge} / \mathrm{Si}$ с квантовыми точками (КT) рассматриваются сегодня как один из объектов для решения этой задачи. Привлекательностью этих структур является наличие в их спектрах люминесценции сигнала при комнатной температуре в области длин волн 1.3-1.6 мкм. Однако существенным недостатком данного типа светоизлучающих структур является низкая квантовая эффективность. Одним из подходов повышения эффективности излучательной рекомбинации носителей заряда в $\mathrm{Ge} / \mathrm{Si}$ структурах является встраивание КТ в микрорезонаторы на основе фотонных кристаллов $(Ф К)[1,2]$. В данной работе рассматриваются следующие возможные способы повышения эффективности источников света на основе КТ: упорядочение взаимного расположения КТ и их встраивание в оптические микрорезонаторы.

Для получения структур с пространственно упорядоченными массивами КТ, встроенными в микрорезонаторы на основе двумерных фотонных кристаллов (ФК), использовались подложки кремний-на-изоляторе (SOI). Создание тестовых образцов проводилось в три этапа. На первом этапе методами электронной литографии и плазмохимического травления были созданы структурированные подложки, представляющие собой периодическую последовательность ямок в виде квадратной решётки с периодом от 0.5 мкм до 6 мкм. На втором этапе методом молекулярнолучевой эпитаксии на структурированных подложках SOI проведено формирование пространственно упорядоченных массивов КТ и групп КТ. Были созданы два типа упорядоченных структур: 1) одиночные квантовые точки внутри ямок, 2) группы квантовых точек, упорядоченных в кольцо вокруг ямок. На третьем этапе была отработана технология создания и пространственного совмещения микрорезонаторов на базе ФК с упорядоченными массивами GeSi KT.

Излучательные свойства структур с пространственно-упорядоченными GeSi KT, встроенными в микрорезонаторы, исследовались методом микро-фотолюминесценции (ФЛ) с высоким пространственным и спектральным разрешением. Обнаружено, что интенсивность люминесцентного отклика возрастает для образцов с ФК по сравнению с интенсивностью от образцов с упорядоченными группами КТ без ФК. Возрастание интенсивности связано с увеличением эффективности вывода излучения из структуры за счет ФК. Ярко выраженные пики ФЛ от КТ наблюдаются в спектральном диапазоне от 0.9 до 1.0 эВ. Показано, что интенсивность сигнала от групп КТ выше, чем от одиночных КТ при одном и том же периоде упорядочения. Обнаружено, что для структур с упорядоченными группами КТ, расположенных с периодом 1 мкм относительно друг друга, наблюдается интенсивный сигнал ФЛ с тонкой структурой из резонансных линий в области свечения GeSi KT. Для структур с одиночными КТ подобного эффекта не наблюдалось.

Работа финансировалась из средств гранта РФФИ № 16-29-14031 в части создания структур с КТ, встроенными в микрорезонаторы, гранта РФФИ № 18-29-20016-мк в части люминесцентных измерений. Электронно-лучевая литография проводилась на оборудовании ЦКП «Наноструктуры».

\section{Лumepamypa}

[1] M. Schatz, F. Hackl, M. Glaser et al. // ACS Pho-tonics, V. 4 (3), 665 (2017).

[2] M. V. Stepikhova, A. V. Novikov, A. N. Yablonskiy et al. //Semicond. Sci. Technol., V. 34, 024003 (2019). 